\title{
Heterotopic Pregnancy after Natural Conception: A Case Report
}

\author{
Heterotope Schwangerschaft bei einer spontan \\ eingetretenen Schwangerschaft: Fallvorstellung
}

Authors

Affiliations

\author{
A. Kratschla-Apochal ${ }^{1}$, C. Nauer ${ }^{2}$, D. Bolla ${ }^{3}$
}

${ }^{1}$ Gynaecology Department, Spital Herisau, Herisau, Switzerland

${ }^{2}$ Gynaecology Department, Spital Herisau, Herisau, Switzerland

${ }^{3}$ Gynaecology Department, Kantonsspital St. Gallen, St. Gall, Switzerland
Key words

- assisted reproduction technology (ART)

- obstetrics

- pregnancy

Schlüsselwörter

- assistierte Reproduktion

- Geburtshilfe

- Schwangerschaft

\section{received 6.3.2012 \\ revised $\quad 5.4 .2012$ \\ accepted 9.4.2012}

Bibliography

Dol http://dx.doi.org/ 10.1055/s-0032-1314993

Geburtsh Frauenheilk 2012; 72 : 639-642 @ Georg Thieme

Verlag KG Stuttgart · New York · ISSN 0016-5751

Correspondence
Dr. Alexandra
Kratschla-Apochal
Spital Herisau
Gynäkologie
Spitalstraße 6
9100 Herisau
Switzerland
alexapochal@yahoo.com

\section{Abstract}

$\nabla$

Heterotopic pregnancy (HP), i.e. the simultaneous development of an intrauterine and an ectopic pregnancy, is rare with a reported incidence of between $1: 2600$ and $1: 30000$. Only a few cases have been described in the literature. We report here on an extremely rare case of HP after natural conception with cardiac activity noted on sonography in both the intrauterine and the ectopic foetus. Examination excluded appendicitis. Vaginal sonography (VS) was performed and revealed a second, extrauterine foetus with cardiac activity. The differential diagnosis included twin pregnancy in a bicornuate uterus, but HP could not be excluded. Diagnostic laparoscopy was scheduled due to progressive abdominal pain. Shortly before surgery the patient became acutely hypotensive. Laparoscopy confirmed a heterotopic pregnancy in the right tube. Due to acute rupture of the extrauterine pregnancy with intraabdominal bleeding, the procedure was converted to a laparotomy with right-sided salpingectomy. Subsequently, the intrauterine pregnancy continued without complications. The intrauterine pregnancy was uneventful with spontaneous delivery at term.

\section{Zusammenfassung \\ $\nabla$}

Spontane heterotope Schwangerschaften (HS), d.h. das gleichzeitige Auftreten einer intrauterinen und extrauterinen Gravidität, sind mit einer Inzidenz zwischen 1:2600 und 1:30000 ein seltenes Ereignis. Wenige solcher Fälle sind in der Literatur beschrieben. Wir berichten über den äußerst seltenen Fall einer HS mit sonografischer Visualisierung der Herzaktion beim intra- und extrauterinen Fetus nach spontaner Konzeption. In unserem Fall konnte eine HS (Differenzialdiagnose: Geminischwangerschaft in einem Uterus bicornis; Appendizitis) durch die Vaginalsonografie (VS) und abdominale Sonografie nicht ausgeschlossen werden. Wegen progredienter Schmerzsymptomatik wurde eine diagnostische Laparoskopie geplant. Kurz präoperativ kam es auf dem Weg in den Operationssaal zu einem akuten Blutdruckabfall. Laparoskopisch konnte eine heterotope Schwangerschaft in der rechten Tube bestätigt werden. Aufgrund der präoperativ akuten Ruptur der Extrauteringravidität und vermehrter intraabdomineller Blutung wurde auf eine Laparotomie umgestiegen und eine Salpingektomie rechts durchgeführt. Die intrauterine Schwangerschaft konnte erhalten werden, und die weitere Schwangerschaft gestaltete sich problemlos mit termingerechter spontaner Entbindung.

\section{Introduction}

$\nabla$

The simultaneous occurrence of an intrauterine and an extrauterine pregnancy is referred to as heterotopic pregnancy (HP). To date, only a few cases of HP after spontaneous natural conception have been reported in the literature. The reported incidence of HP in a spontaneous cycle is between $1: 2600$ and $1: 30000$. The morbidity and mortality associated with HP are directly correlated to the time between the first occurrence of symptoms and the final diagnosis [4]. Early diagnosis of heterotopic pregnancy is difficult. Most cases of HP are diagnosed between the 5th and 34th gestational week (GW); $70 \%$ of cases are diagnosed between the 5 th and the 8 th GW, 20\% between the 9th and the 10th GW and the remaining $10 \%$ after the 10 th GW $[10,11]$. We report here on a very rare case of HP with sonographic visualisation of cardiac activity in the intrauterine 


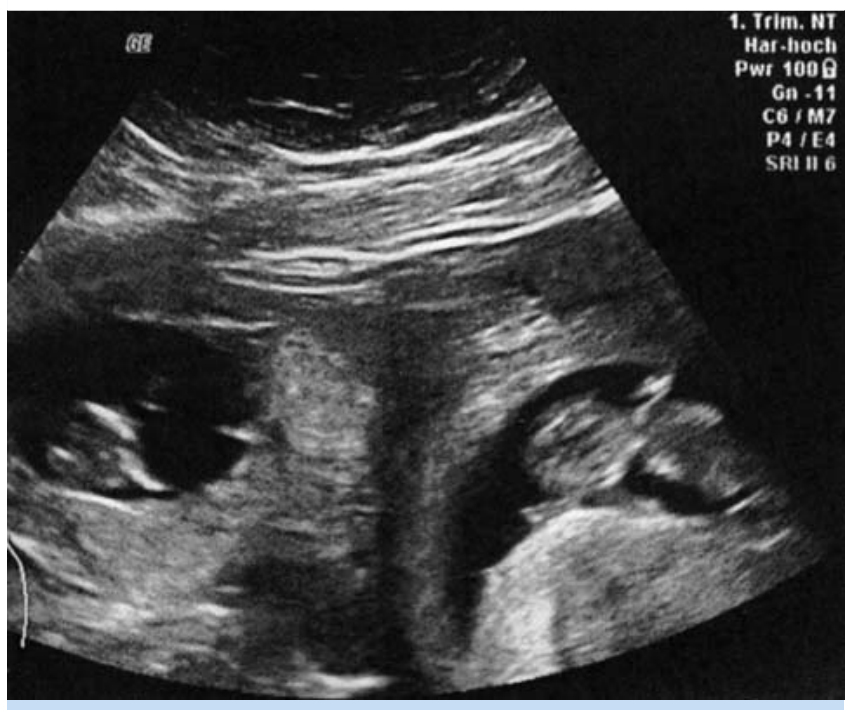

Fig. 1 Abdominal ultrasound: intact extrauterine and intact intrauterine pregnancy.

and extrauterine foetuses in a spontaneously occurring pregnancy.

After describing the case, we discuss the risk factors and the difficulties in diagnosing HP as well as the therapeutic options.

\section{Case Report}

$\nabla$

A 33-year-old gravida III, para I was admitted to the Herisau Cantonal Hospital in gestational week 10 1/7 with sudden, acute, intermittent, diffuse and paroxysmal abdominal pain. On admission, the patient additionally complained of nausea and dizziness but did not present with any other symptoms. There was no vaginal bleeding. The patient was haemodynamically stable with an $\mathrm{Hb}$ of $116 \mathrm{~g} / \mathrm{l}$ and slightly raised inflammatory parameters (leukocytes $15.3 \mathrm{G} / \mathrm{l}$, C-reactive protein $16.6 \mathrm{mg} / \mathrm{l}$ ). Blood pressure and pulse were within normal ranges. The patient had a previous history of 4-level thrombosis in her first pregnancy (2004), which was treated for 1 year with Marcoumar, and after giving birth spontaneously she had required curettage postpartum for a retained placenta. Subsequent coagulation workup showed no indications of congenital or acquired thrombophilia. Additional risk factors were obesity (BMI 36) and nicotine abuse (5 py).

The spontaneously occurring pregnancy had been previously unremarkable. The patient had undergone an antenatal check-up by her gynaecologist 2 weeks before she was admitted to hospital. This previous check-up had shown an intact intrauterine singleton pregnancy commensurate with her amenorrhea.

On presentation to hospital sonography was done to exclude appendicitis. Vaginal sonography and abdominal sonography confirmed the presence of an intrauterine embryo with good vital signs and a crown-rump length (CRL) of $4.35 \mathrm{~cm}$. A second embryo with vital signs was found on the right side above the 1st amniotic sac with a CRL of $3.93 \mathrm{~cm}$ ( $\bullet$ Fig. 1 ). It proved to be difficult to delineate the amniotic cavity around the right-sided embryo sonographically. The question was therefore whether the patient had a bicornuate uterus as no lateral cervical pain was reported and the patient was haemodynamically stable without abdominal guarding. The patient was admitted to hospital for

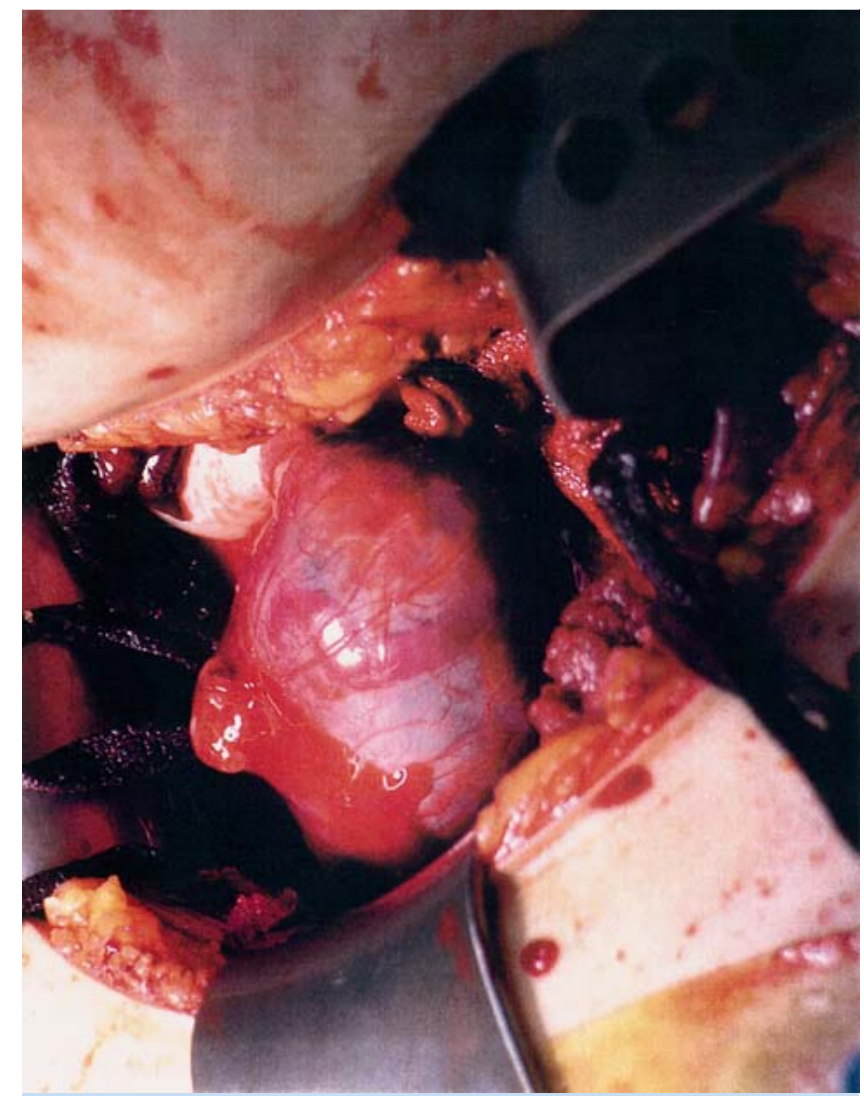

Fig. 2 Intraoperative finding of an extrauterine pregnancy in the right tube.

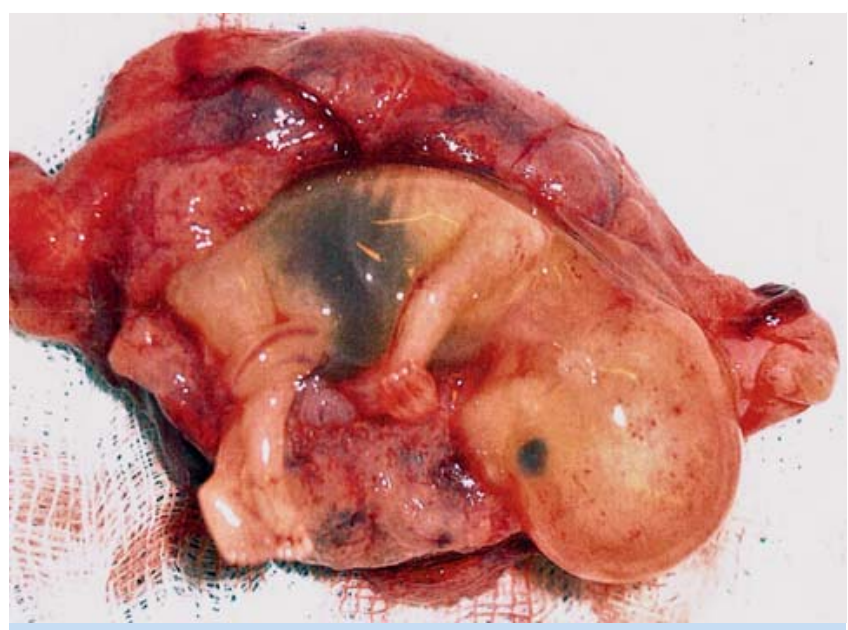

Fig. 3 Extrauterine pregnancy in the right tube.

further observation. Despite the administration of analgesics the pain attacks became increasingly acute and frequent. Because of the progressive symptoms and because it was not possible to exclude HP, the patient was scheduled for diagnostic laparoscopy. On the way to the operating room the patient became acutely hypotensive. Because of acute intraabdominal bleeding from the ruptured ectopic pregnancy the laparoscopic procedure was converted into a Pfannenstiel laparotomy ( Figs. 2 and 3). Intraoperatively, a ruptured $6-\mathrm{cm}$ HP was found in the ampullary por- 
tion of the right fallopian tube. A right-sided salpingectomy was performed without complications. Postoperatively, the patient received 2 units of packed red blood cells due to a blood loss of approx. $2000 \mathrm{ml}$. There were no postoperative complications, and subsequently the intrauterine pregnancy was uneventful. The patient gave birth to a healthy baby girl (gestational age 39 6/7) without difficulties. Delivery was spontaneous and the baby had a birth weight of $3010 \mathrm{~g}$. Manual placenta removal was required for retained placenta and was performed without complications.

\section{Discussion}

$\nabla$

Over the past 20 years with the development of assisted reproductive medicine, the numbers of cases of HP have increased significantly $[3,6,9]$. However, heterotopic pregnancy occurring in spontaneous pregnancy is still very rare. Early diagnosis of such cases is very difficult because the ectopic pregnancy is often overlooked once the intrauterine pregnancy has been confirmed. The causes of HP are the same as those cited for ectopic pregnancies ( Table 1). In most patients, diagnosis is usually late and often occurs in an emergency situation. The most common symptoms described in the literature are diffuse abdominal pain (83\% of cases) and hypovolemic shock with guarding (13\% of cases), with vaginal bleeding occurring in only $50 \%$ of patients [9].

Transvaginal ultrasound is the method of choice for the diagnosis of HP $[7,8]$. In general, it is recommended that investigations include both transabdominal and transvaginal sonography to ensure that higher-lying extrauterine pregnancies are not missed [4].

Differentiating between an extrauterine pregnancy and a haemorrhagic corpus luteum cyst can be particularly difficult. In such cases, the increased echogenicity arising from trophoblast invasion of the tubal or ovarian wall compared to the wall of the corpus luteum may be a possible criterion for a better differentiation [10]. As in our patient with HP, most ectopic pregnancies are tubal or angular, in rare cases they also occur in cervical, ovarian, or peritoneal locations [4]. When treating women attempting to conceive with assisted reproduction technology, some authors recommend transferring only a few embryos to prevent HP. The risk of a HP increases with the number of transplanted embryos [4]. The literature suggests that quantitative monitoring of beta-HCG levels may not be useful for the detection of HP. Insufficient beta-HCG production, which occurs with extrauterine pregnancy, is obscured by the normal values generated by the intrauterine pregnancy $[4,9,10]$.

Nowadays, diagnostic laparoscopy together with vaginal sonography are the gold standard when heterotopic pregnancy is suspected $[4,11]$. Treatment can then be carried out immediately if the presence of HP is confirmed. In a review of 80 cases with HP treated surgically, the survival rate of the intrauterine pregnancies was $68.7 \%$ [1].

Another method to treat HP is local use of foeticidal agents such as methotrexate (MTX) or potassium chloride $(\mathrm{KCl})$ in asymptomatic patients [4]. However, there is currently no data available with regard to the effect of locally injected MTX on intrauterine foetal development or on the development of the child postpartum [4]. For this reason, several authors have recommended using $\mathrm{KCl}$ rather than MTX for selective foeticide in an ectopic pregnancy $[5-7,11]$. The disadvantage of $\mathrm{KCl}$ is that it may not entirely inhibit trophoblast invasion and that trophoblastic tissue
Table 1 Risk factors for extrauterine pregnancy and heterotopic pregnancy [4].

\begin{tabular}{|lll|}
\hline Degree of risk & Risk factors & Odds ratio \\
Greatly & status post extrauterine pregnancy & 6.4 \\
increased risk & positive for Chlamydia trachomatis & 4.6 \\
& status post tubal operation & 4.0 \\
\hline Moderately & status post adnexitis & 3.4 \\
increased risk & promiscuity (over 5) & 1.6 \\
& cigarettes (10-19/day) & 3.1 \\
& cigarettes (over 20/day) & 3.9 \\
& age (over 40 years) & 2.9 \\
& status post spontaneous abortion (>3) & 3.0 \\
\hline Slightly & sterility & $2.1-2.7$ \\
increased risk & status post IUD & 1.3 \\
& age (30-34 years) & 1.3 \\
& age (35-39 years) & 1.4 \\
& status post nicotine abuse & 1.5 \\
& cigarettes (1-9/day) & 1.7 \\
& status post spontaneous abortion (1-2) & 1.2 \\
& status post abruptio placentae & $1.1-2.8$ \\
& status post ruptured appendicitis & 1.4 \\
\hline
\end{tabular}

will not be completely resorbed, thus necessitating an additional surgical intervention [3]. Baxi et al. [2] described a case of successful expectant management of a heterotopic pregnancy.

\section{Conclusion}

Heterotopic pregnancy is very rare in spontaneously occurring pregnancies and is associated with increased mortality of mother and baby. For this reason we recommend close and careful investigation in every case where the clinical or sonographic adnexa findings in an asymptomatic patient are unclear. Laparoscopy may be the gold standard for HP, but diagnostic laparoscopy should be used conservatively in pregnant patients and is generally only indicated in clinically symptomatic patients.

\section{Conflict of Interest \\ $\nabla$}

None.

\section{References}

1 Barrenetxea G, Barinaga-Rementeria L, Lopez de Larruzea A et al. Heterotopic pregnancy: two cases and a comparative review. Fertil Steril 2007; 87: 417.e9-417.e15

2 Baxi A, Kaushal M, Karmalkar HK et al. Successful expectant management of tubal heterotopic pregnancy. J Human Reprod Sci 2010; 3: $108-110$

3 Bornstein E, Berg $R$, Santos $R$ et al. Term singleton pregnancy after conservative management of a complicated triple gestation including a heterotopic cornual monochorionic twin pair. J Ultrasound Med 2011; 30: 859-867

4 Diesch HC. Heterotope Schwangerschaft - eine aktuelle Literaturübersicht. Speculum 2005; 23: 17-21

5 Knitza R, Bollman W, Kolben M. Erfolgreiche operative Behandlung einer heterotopen - interstitiellen und intrauterinen - Schwangerschaft nach In-vitro-Fertilisierung (IVF). Geburtsh Frauenheilk 2007; 67: 480-482

6 Kriplani A, Lunkad A, Sharma M et al. Recurrent ectopic pregnancy with heterotopic pregnancy in a patient of hypogonadotropic hypogonadism. A case report. J Reprod Med 2011; 56: 274-276 
7 Lautmann K, Staboulidou I, Wüstmann M et al. Heterotopic pregnancy: simultaneous intrauterine and ectopic pregnancy following IVF treatment with the birth of a healthy child. Ultraschall in Med 2009; 30: 71-73

8 Ludwig M, Kaisi M, Bauer O et al. Heterotopic pregnancy in a spontaneous cycle: do not forget about it! EJOGR 1999; 87: 91-93

9 Sturlese E, Retto G, Palmara A. Heterotopic pregnancy: case report. Clin Exp Obst And Gyn 2010; 37: 69-72
10 Varras $M$, Akrivis C, Hadjopoulos $G$ et al. Heterotopic pregnancy in a natural cycle presenting with tubal rupture: a case report and review of literature. EJOGR 2003; 106: 79-82

11 Zullo F, Pellicano, Di Carlo C et al. Heterotopic pregnancy in a woman without previous ovarian hyperstimulation: ultrasound diagnosis and management. EJOGR 1996; 66: 193-195

Deutschsprachige Zusatzinformationen online abrufbar unter: www.thieme-connect.de/ejournals/toc/gebfra. 